Revista de Derecho

de la Pontificia Universidad Católica de Valparaíso

LIV (Valparaíso, Chile, 1er semestre de 2020)

[pp. 67 - 94]

\title{
LA LEY COMO FUENTE DE LAS OBLIGACIONES MODALES. EL CASO DE LA LEY No 13.080
}

(The law as source of the obligations of the mode. The case of law No 13.080)

\author{
Cristián Aedo Barrena* \\ Alexis Mondaca MirandA**
}

\section{RESUMEN}

En el presente artículo se estudia la ley como fuente del modo. Para comprender mejor nuestro vigente sistema de fuentes de las obligaciones. En primer lugar, se hace un recorrido histórico relativo a las mismas, lo que permite entender por qué los actos jurídicos unilaterales no son fuente de obligaciones. Con posterioridad se dilucida la naturaleza jurídica del modo, lo que exige investigar las nociones de modo-obligación y de modo-carga. Finalmente se analiza la Ley No 13.080, texto que establece un modo que presenta particularidades de relevancia para nuestra investigación.

\section{Palabras clave}

Derecho civil - modo - obligación ley - fuente de las obligaciones.

\section{ABSTRACT}

In the present article the law is studied as the source of the mode. To better understand our current system of sources of obligations. First, a historical tour is made relative to them, which allows us to understand why unilateral legal acts are not a source of obligations. Subsequently the legal nature of the mode is elucidated, which requires investigating the notions of modeobligation and load-mode. Finally, Law No 13,080 is analyzed, a text that establishes a mode that presents particularities of relevance for our research.

\section{KeYwords}

Civil Law - mode - obligation law - sources of obligations.

Recibido el 7 de junio de 2019 y Aprobado el 9 de julio de 2020.

* Profesor de Derecho civil de la Facultad de Derecho de la Universidad Católica de la Santísima Concepción. Doctor en Derecho por la Universidad de Deusto. Dirección postal: calle Lincoyan No 255, Concepción. Correo electrónico: caedo@ ucsc.cl

** Profesor de Derecho civil de la Facultad de Ciencias Jurídicas y Sociales de la Universidad de Talca. Doctor en Derecho por la Pontifica Universidad Católica de Valparaíso. Máster en Derecho, Empresa y Justicia por la Universidad de Valencia. Dirección postal: 2 Norte No 685, Talca. Correo electrónico: alexis.mondaca@ utalca.cl. 


\section{INTRODUCCIÓN}

El modo no ha sido una materia sobre la que haya recaído el principal interés de la doctrina nacional. Podemos afirmar que, dentro del tema de las modalidades, la mayor cantidad de monografías y de obras de literatura jurídica en general, se ha centrado a propósito de la condición y del plazo, principalmente sobre la primera en su carácter resolutorio ${ }^{1}$. Tampoco abundan pronunciamientos jurisprudenciales relativos al modo. El escenario descrito ha suscitado nuestro interés en estudiar el modo de origen legal.

En efecto, el presente artículo versa sobre el modo, en específico, sobre la obligación modal que reconoce a la ley como fuente de las obligaciones. En esta parte, de suma utilidad resulta el estudio de los antecedentes históricos, puesto que permiten comprender de mejor manera la disciplina otorgada por Andrés Bello a las fuentes de las obligaciones, en las que no se incluyeron los actos jurídicos unilaterales, como el testamento, respetando con ello la tradición del Derecho romano.

Una vez afirmada dicha génesis del modo, para efectos de precisar de manera adecuada la naturaleza jurídica de éste, nos ocuparemos del estudio de la dualidad modo-obligación y modo carga. Luego para un mejor tratamiento de la cuestión, se dedican líneas al análisis de la tríada obligación, deber y carga. Todo lo señalado nos permitirá fundamentar que, por regla general, el modo es una obligación, aunque como tal presenta notas particulares.

En la sección final de esta investigación se analiza la Ley No 13.080 de 5 de noviembre de 1958. Hemos decidido referirnos a esta ley porque nos permite ilustrar y aplicar las materias analizadas en este trabajo en forma precedente. Así, en primer lugar, sostendremos que la Ley No 13.080 estableció un modo en favor de la persona jurídica Club Hípico de Antofagasta. En segundo término, nos pronunciaremos sobre las características

${ }^{1}$ Se ha abandonado la idea de que la resolución por incumplimiento sea una causa de ineficacia contractual, como ocurre con la condición ordinaria (especialmente la resolutoria), sino que, por el contrario, se trataría de un efecto popio de la eficacia contractual frente al incumplimiento. Ha contribuido a la proliferación de textos relacionados con la resolución el auge que ha tenido en la dogmática chilena las nuevas nociones de remedios concedidos al acreedor, en el contexto de la función realista del contrato. Por mencionar solo algunos: Morales Moreno, Antonio Manuel, El propósito práctico y la idea de negocio jurídico en Federico de Castro, en el mismo, Modernización del Derecho de obligaciones (Madrid, Thomson Civitas, 2006), pp. 323-326; y Vidal Olivares, Álvaro, La noción de incumplimiento esencial en el Código Civil, en Revista de Derecho de la Pontificia Universidad Católica de Valparaíso 27 (2009), pp. 226-227. 
propias de dicho modo, entre éstas, la coincidencia entre asignatario modal y beneficiado.

Finalmente, sobre la base la característica recientemente mencionada, nos referiremos a los escenarios posibles ante el evento de incumplimiento del modo.

\section{El MOdO, MODALIDAD DEL ACTO JURÍDiCO. LA LEY COMO FUENTE DE LA OBLIGACIÓN MODAL}

La modalidad es una categoría dogmática que se encuentra disciplinada de un modo difuso y bifronte. De manera difusa, porque no hay en el cuerpo del Código civil una regulación sistemática de las modalidades. En efecto, el Código civil ha tratado, tanto en las asignaciones testamentarias, como en las obligaciones, las modalidades clásicas: condición, plazo y modo. Es bifronte, dado que la modalidad bien recae sobre el acto jurídico, bien acompaña el efecto de la declaración de voluntad.

En doctrina, las modalidades de los actos jurídicos se caracterizan porque alteran los efectos normales de los actos mismos ${ }^{2}$. Ello explica que, como regla general, se les considere elementos accidentales del acto jurídico, aunque nada obsta a que estemos en presencia de elementos de la naturaleza (como la representación en el mandato o la condición resolutoria tácita en los contratos bilaterales) o de la esencia (la condición de existencia en el fideicomiso). A las modalidades clásicas ya referidas, la doctrina agrega las denominadas "modalidades modernas": la representación, en cuanto concurre una voluntad a la realización del acto (la del representante), pero los efectos jurídicos se radican en otro (el representado); la solidaridad pasiva; la indivisibilidad, las obligaciones alternativas y "la facultad de pago de una cosa por otra" 3 .

Como se ha referido antes, la regulación de las modalidades es bifronte. Y ello es porque puede ser sujeto a modalidad, tanto el acto jurídico, como la obligación. En efecto, el acto mismo puede estar sujeto a modalidad, como por ejemplo la venta de las cosas que se espera que existan ${ }^{4}$ o la

2 Por todos, León Hurtado, Avelino, La voluntad y la capacidad en los actos jurídicos (reimpresión de la 3a edición, Santiago, Editorial Jurídica de Chile, 1990), p. 26

${ }^{3}$ Claro Solar, Luis, Explicaciones de Derecho civil chileno y comparado (Santiago, Editorial Jurídica de Chile, 2015), V, p. 71.

${ }^{4}$ En palabras de Alessandri Rodríguez, "lo que se vende es la cosa misma que no existe, pero se espera que exista, en cuyo caso la venta se hace bajo condición suspensiva, que llegará a perfeccionarse si la cosa existe; de lo contrario no hay contrato", ALESSANDRI 
venta de cosas a prueba o gusto 5 (artículos 1813 y 1823 del Código civil). Hay casos en que el Código civil limita expresamente la modalidad en los actos jurídicos, como la aceptación o repudiación de una herencia, que no puede estar sujeta a condición o plazo (artículo 1227 del Código civil) ${ }^{6}$. Como regla general, sin embargo, aunque la modalidad se pacte en el acto jurídico, ésta recae en la obligación que se genera como consecuencia de éste, directa o indirectamente.

Las modalidades clásicas se encuentran tratadas en las asignaciones testamentarias y en las clases de obligaciones, a propósito de los efectos de las mismas y de los contratos. Si bien es cierto que las disposiciones se aplican recíprocamente, existe una diferencia fundamental en las normas que rigen los referidos institutos. A mayor detalle, en el caso de las asignaciones testamentarias, la fuente de la obligación no es el acto jurídico (esto es, el testamento), sino la ley. En cambio, a propósito del contrato, pactada la modalidad, ésta afecta a las obligaciones nacidas de aquél.

Las obligaciones surgen entonces sólo de aquellas fuentes que se encuentran precisamente preestablecidas por la ley, lo que implica una limitación a la libertad económica de los individuos. En este sentido, para muchos autores las fuentes de las obligaciones equivalen a lo que en la teoría de la causa conocemos como "causa eficiente", o sea, su antecedente generador. Considerando lo señalado, Peñailillo las define de la siguiente manera: "los hechos o actos de donde las obligaciones surgen". Abeliuk conceptualiza también las fuentes de las obligaciones en los mismos términos ${ }^{8}$.

Las fuentes de las obligaciones han sido clasificadas tradicionalmente en cinco figuras: el contrato, el cuasicontrato, el delito, el cuasidelito y la ley (la última se agregó posteriormente por los comentaristas del Derecho

Rodríguez, Arturo, De la compraventa y de la promesa de venta (Santiago, Editorial Jurídica de Chile, 2003), I/1, p. 192.

${ }^{5}$ A propósito de la venta al gusto, se ha discutido si estamos en presencia de una condición suspensiva o resolutoria, véase, Goldenberg Serrano, Juan Luis, Venta al peso, cuenta o medida y venta al gusto, en CONTARDo GonZÁlez, Juan Ignacio y DE la Maza Gazmuri, Iñigo (directores), La compraventa. Estudios (Santiago, Thomson Reuters, 2017), pp. 201-205.

${ }^{6}$ Siguiendo a Elorriaga, no se permite aceptar o repudiar bajo modalidad dado que, en la sucesión, además del interés del asignatario, coexisten intereses pertenecientes a otras personas, Elorriaga de Bonis, Fabián, Derecho Sucesorio (Santiago, LexisNexis, 2005), p. 78.

7 Peñallillo Arévalo, Daniel, Las obligaciones. Teoría general y clasificaciones. La resolución por incumplimiento (Santiago, Editorial Jurídica de Chile, 2003), p. 129.

${ }^{8}$ Abeliuk Manasevic, René, Las obligaciones (Santiago, Editorial Jurídica de Chile, 2000), I, p. 45. 
Romano). ${ }^{9} \mathrm{Al}$ respecto, Von Tuhr indica: "En la sistemática del Derecho civil es fundamental la clasificación romana de la obligación en dos grupos principales: obligaciones ex contractu y obligaciones ex delicto. Esta división hubo de ser completada más tarde por otras dos categorías accesorias: obligaciones quesi ex contractu, semejantes por su contenido a las obligaciones contractuales, aunque entre sus hechos constitutivos faltase el elemento esencial del contrato: el acuerdo de voluntades, y obligaciones quasi ex delicto, o sea los deberes de indemnización que no tenían por fundamento el requisito esencial del delito, la culpa"10.

El origen de esta clasificación arranca del Derecho romano. En la res cotidianae de Gayo, D. 44, 7, 1pr., las obligaciones nacen del contrato, del delito y de otras varias causas (variae causarum figurae). Dice el pasaje: "Las obligaciones nacen sea de un contrato, sea de un maleficio, sea de cierto derecho, por distintos tipos de causa". Con posterioridad, en las Instituciones de Justiniano, 3, 13, 2 se habría especificado la última expresión y habrían quedado configuradas las cuatro fuentes que permanecieron por muchos siglos antes que se le agregara la ley.

Como señala d' Ors: "Resulta así la siguiente clasificación de las fuentes de las obligaciones civiles y pretorias: delitos, préstamos, estipulaciones y contratos; esta clasificación no aparece enunciada en las obras escolásticas antiguas y modernas, pero corresponde a la realidad del sistema clásico de formas de obligarse y sus acciones correspondientes. Justiniano siguiendo una clasificación que aparecería ya en Gayo, considera que todo convenio obligacional es un "contrato", por lo que distingue las obligaciones de contrato de las de delito, y luego divide las que no entran en ninguno de los dos conceptos en "cuasi-contractuales" o "cuasidelictuales", según la mayor similitud con uno u otro grupo" ${ }^{11}$. Guillermo Floris enseña que Gayo sostenía, todavía a mediados del siglo II, en sus Instituciones, que todas las obligaciones nacían de contratos o de delitos. Pero en el Digesto, al citarse nuevamente a Gayo, en relación con este tema, se le hace añadir -por interpolación- una nueva fuente de obligaciones, un poco nebulosa: variae

${ }^{9}$ Alessandri Rodríguez, Arturo, Somarriva Undurraga, Manuel y Vodanovic H., Antonio, Tratado de las Obligaciones. De las obligaciones en general y sus diversas clases (2a edición ampliada, Santiago, Editorial Jurídica de Chile, 2000), I, p. 29. Como indica Fabrè Magnan: "Selon la présentation la plus classique, une personne ne peut etre obligeé evers une autre que lorsque l'une ou l'autrede ces cinq sources est presenté: la loi, un contrat, un quasi-contrat, un délit ou en fin un quasi-délit", FABrè MAGNAN, Muriel, Les Obligations (París, PUF, 2004), p. 6.

${ }^{10}$ Von Tuhr, A., Tratado de las Obligaciones (trad. de Roces, W., Madrid, Reus, 1999), p. 31.

${ }^{11}$ D'Ors, Álvaro, Derecho Privado Romano (9a edición, Pamplona, Ediciones Universidad de Navarra, 1997), p. 420. 
causarum figurae $e^{12}$. Posteriormente Justiniano, de acuerdo con su concepción de que no hay contrato sin consentimiento, dividió las obligaciones contractuales en dos categorías: obligaciones de contratos y obligaciones como de contratos (quasi ex contracto), incluyendo en esta última los negocios no convencionales. García Garrido afirma que un deseo de simetría llevó a Justiniano a distinguir entre obligaciones derivadas de delito y las que venían como de delito, pero comenta que su distinción fue arbitraria, por cuanto carecía de una concepción de delito. Finalmente, señala: "Los intérpretes griegos del derecho justinianeo cambiaron ligeramente la nomenclatura de la cuatripartición, al decir que las obligaciones derivan del contrato o cuasicontrato, del delito o cuasidelito. Esta terminología es la que ha pasado a la sistemática moderna"13.

Nuestro Código civil, siguiendo la tradición del Derecho romano, adoptó esta clasificación y distingue así las cinco fuentes antes referidas. El artículo 1437 enumera las fuentes de las obligaciones en nuestro Derecho civil: "Las obligaciones nacen, ya del concurso real de las voluntades de dos o más personas, como en los contratos o convenciones; ya de un hecho voluntario de la persona que se obliga, como en la aceptación de una herencia o legado y en todos los cuasicontratos; ya consecuencia de un hecho que ha inferido injuria o daño a otra persona, como en los delitos y cuasidelitos; ya por disposición de la ley, como entre los padres y los hijos sujetos a patria potestad". Por su parte, el artículo 2284 versa: "Las obligaciones que se contraen sin convención, nacen o de la ley, o del hecho voluntario de una de las partes. Las que nacen de la ley se expresan en ella. Si el hecho de que nacen es licito, constituyen un cuasicontrato. Si el hecho es ilícito y cometido con intención de dañar, constituye un delito. Si el hecho es culpable pero cometido sin intención de dañar constituye un cuasidelito. En este titulo se trata solamente los cuasicontratos".

Ahora bien, la no inclusión de los actos jurídicos unilaterales como fuente obligacional, se debe a la adopción de la tradición romana. El sistema de fuentes nos revela que en el Derecho romano la principal manifestación de voluntad reconocida fue el contrato. No se conoció, como

${ }^{12}$ Floris Magadant, Guillermo, El Derecho Privado Romano (17a edición, Ciudad de México, Esfinge, 1991), p. 315. En efecto, siguiendo GarCía Garrido, Manuel, Derecho Privado Romano. Casos, acciones, instituciones (7a edición, Madrid, Editorial Dykinson, 1998), pp. 476-478, Gayo afirmaba: "Pasemos ahora a las obligaciones, cuya principal división abarca dos clases: pues toda obligación nace o de un contrato o de un delito". Posteriormente, en el tratado postclásico de la jurisprudencia de las cosas, se agrega la referencia a los varios tipos de causas.

${ }^{13}$ Ibid, pp. 476-480. 
categoría dogmática, la declaración unilateral de voluntad, sin perjuicio del perfilamiento de actos jurídicos unilaterales, como el testamento ${ }^{14}$.

Debe descartarse, por consiguiente, que el testamento opere como fuente obligacional. La sucesión por causa de muerte, como sabemos, es un modo de adquirir, en el sistema de Bello, un derecho real en particular, el de herencia, que, según la doctrina, constituye una universalidad jurídica. Como afirma Somarriva, de las distintas categorías de indivisión, la que distingue entre indivisión sobre una cosa universal e indivisión sobre una cosa singular, que es la que nos interesa, está expresamente reconocida en nuestra legislación, por cuanto, la primera parte del inciso $1^{\circ}$ del artículo 1317, dispone: "Ninguno de los coasignatarios de una cosa singular o universal será obligado a permanecer en la indivisión". Para Somarriva, estamos en presencia de una indivisión que recae sobre una cosa universal, cada vez que la comunidad recaiga sobre un patrimonio, es decir, un conjunto de bienes y pasivos, distinto del patrimonio, que antes de los indivisarios, ha tenido otro titular. En cambio, si la comunidad tiene por objeto bienes determinados, no estamos en presencia de una indivisión sobre cosa universal ${ }^{15}$.

Las diferencias entre ambos tipos de indivisión son considerables. Según el profesor Somarriva, en la comunidad sobre una universalidad, se producen las siguientes consecuencias: en principio, el derecho del comunero es indeterminado, como el nombrado autor lo denomina, "flotante", que sólo va a determinarse hecha la partición. ${ }^{16}$ Ello es precisamente lo que

${ }^{14}$ En este sentido, por todos, Arangio-Ruiz, Vicenzo, Istituzioni di Diritto Romano (14a edizione, Napoli, Casa Editrice Dott. Eugenio Jovene, 2012), p. 292.

${ }^{15}$ Somarriva Undurraga, Manuel, Indivisión y partición (reimpresión de la $5^{\text {a }}$ edición, actualizada por, Gonzalo Figueroa Yáñez, Santiago, Editorial Jurídica de Chile, 2006), pp. 39-42. Véase también a Silva, para quien una universalidad jurídica se caracteriza porque está compuesta de bienes y deudas, con un activo y un pasivo correlativo de una masa de bienes. La comunidad de hecho, en cambio, está conformada por un conjunto de activos, pero carece completamente de pasivos. Aún así, este autor no comparte la opinión de Somarriva, en orden al reconocimiento legal de las universalidades jurídicas. Considera, por el contrario, que el artículo 2304, al referirse a las comunidades sobre cosa universal, están pensando en universalidades de hecho, no de derecho, porque la regulación del cuasicontrato de comunidad fue tomada de Pothier y este autor sólo se refería a las comunidades de hecho. Agrega que en la universalidad jurídica no puede hablarse de indivisión, puesto que el pasivo no permanece intacto al transmitirse a varios titulares; por el contrario, éste se distribuye entre los varios herederos. De este modo, piensa, sólo entre las cosas que no se dividen ipso iure puede hablarse de comunidad, por lo que, en la sucesión, estaríamos en presencia de una comunidad de hecho y no de derecho, SiLVA Segura, Enrique, Acciones, actos y contratos sobre cuotas (Santiago, Editorial Jurídica de Chile, 1985), pp. 54-55.

${ }^{16}$ Somarriva, cit. (n. 15 ), pp. 40-41. La comunicabilidad de la cuota con los 
justifica, en su concepto, el efecto declarativo de la partición, conforme al artículo 1344 del Código civil. Como el derecho tiene carácter indeterminado, en otros términos, no se comunica con los bienes que componen la indivisión, la tradición no se sujeta a las reglas de los bienes raíces, ni puede rescindirse la compraventa, por ejemplo, por lesión enorme ${ }^{17}$. En la indivisión sobre cosa singular, los efectos son los inversos ${ }^{18}$.

Desde luego, nada obsta a que mediante la sucesión por causa de muerte se puedan adquirir otros derechos reales, como el dominio (pensemos en el legado de especie o cuerpo cierto). La sucesión, que opera en virtud de la muerte del causante, puede vehicular la voluntad del causante a través del testamento, en el que éste declara su voluntad en orden a disponer de sus bienes, con arreglo a un sistema limitado, habiendo legitimarios (artículo 1184 del Código Civil). Si el causante no dispuso, si no ha dispuesto conforme a derecho o sus disposiciones no tienen en efecto, la ley regula la

bienes que componen la comunidad es una cuestión sumamente compleja y debatida en la doctrina. Como explica Peñailillo, la doctrina dominante, admitiendo que el Código se inspira en la concepción romana, entiende que no se ha seguido dicha concepción en este punto, recayendo el derecho de cada comunero en la cosa común y no en los bienes que la componen, lo que explicaría el efecto declarativo de la partición. Sin embargo, agrega que se ha puesto en duda esta concepción, por cuanto hay buenos argumentos para entender que en el Código civil se consagra la comunicación entre la cuota y los bienes individuales, Peñailillo Arévalo, Daniel, Los bienes. La propiedad y otros derechos reales ( $3^{\text {a }}$ edición, Santiago, Editorial Jurídica de Chile, 2002), pp. 102-103.

${ }^{17}$ Como señalan Alessandri, Somarriva y Vodanovic, cada copropietario es considerado dueño individual y exclusivo de su cuota-parte, pero la suerte de los actos sobre esa cuota-parte quedan subordinados a las resultas de la partición, ALESSANdri Rodríguez, Arturo, Somarriva Undurraga, Manuel - Vodanovic H., Antonio, Tratado de los Derechos reales (6 ${ }^{\mathrm{a}}$ edición, Santiago, Editorial Jurídica de Chile, 2001), I, pp. 112-113. Para Vodanovic, en la universalidad de derecho, se forma un conjunto orgánico, creado por ley, de relaciones jurídicas activas y pasivas pertenecientes a un mismo sujeto y que se miran como un todo unitario en consideración a un fin determinado, Vodanovich H., Antonio, Manual de Derecho Civil. Parte preliminar y general (Santiago, Editorial Conosur, 2001), pp. 356-357.

${ }^{18}$ Aún así, debe advertirse que, siguiendo a Somariva, en la comunidad singular, si bien es cierto debería llegarse a la conclusión de la inaplicabilidad del efecto declarativo, las disposiciones legales, especialmente el artículo 1317, que reconoce ambos tipos de indivisión, no permite dudar sobre el alcance de la norma, es decir, que el título (incluyendo el efecto declarativo), se aplicaría tanto a las comunidades universales, como singulares, claro que, en este caso, estaríamos frente, siempre según Somarriva, a una verdadera ficción, SOMARriva, cit. (n. 15), p. 465. Véase, también, Somarriva Undurraga, Manuel, Derecho Sucesorio (7a edición actualizada, versión de Abeliuk, René, Santiago, Editorial Jurídica de Chile, 2005), II, p. 639. 
sucesión (artículos 988 y siguientes del Código Civil). Por último, puede ser ésta, parte testada y parte intestada.

Este es el sistema, grosso modo, de la sucesión por causa de muerte para la adquisición de derechos reales y la forma en la que se integra el testamento. Luego, ¿cómo opera el mecanismo en el caso de los derechos personales u obligaciones? Hay dos formas. En primer término, la relación testamento-obligación está delimitada a las deudas hereditarias: el testador puede imponer a alguno de los herederos cargas u obligaciones diferenciadas, o bien distribuir de otro modo la división legal (artículos 1354 y siguientes del Código civil). En segundo lugar, a propósito de los legados, por cuanto los legados de género constituyen un derecho personal a favor del legatario (artículos 1112 y 1115 del Código civil).

En el primer caso nombrado, puede ocurrir que la obligación que se transmite a los herederos sea en razón de que éstos son parte de la convención que dio lugar a la obligación, o cuando el testador impone una carga directamente (como la obligación de pagar un legado de género). En estos supuestos, la fuente de la obligación que nace es la ley. Para el caso de los legados de género, la conclusión es la misma.

Todo el análisis anterior que se ha realizado nos permite sostener que el modo, en tanto modalidad del acto jurídico, pero trasladable a la obligación, puede ser establecida en razón de la ley. En principio, no existen fundamentos para excluir a alguna de las cinco fuentes de las obligaciones que reconoce nuestro sistema como origen del modo. Sin perjuicio de lo anterior, no parece viable pensar en un modo surgido de un cuasicontrato, de un delito o de un cuasidelito. Esta materia ha sido estudiada por Guzmán Brito, autor que ha precisado lo siguiente: "De estar a la rúbrica del título 4o: De las obligaciones modales, del libro IV del CC. y a su artículo 1493, las obligaciones sujetas a modo, o modales, son posibles con respecto a las nacidas de cualquier fuente; pero es claro que el modo no puede tener lugar en las obligaciones cuasicontractuales, que no estén fundadas en un legado aceptado, delictuales ni cuasidelictuales y sólo teórica aunque raramente en las legales" ${ }^{19}$.

En definitiva, considerando lo señalado precedentemente, podemos afirmar que, por regla general, la fuente de las obligaciones del modo será el contrato, y en forma excepcional la ley. Centrándonos en lo último, a continuación, analizaremos la naturaleza jurídica del modo para con posterioridad referirnos a la posibilidad de que en la Ley No 13.080 se hubiese establecido un modo directamente y, en su caso, las notas propias de éste.

\footnotetext{
${ }^{19}$ GuZmán BRITO, Alejandro, Estudios sobre los legados según el Derecho civil chileno (Santiago, Abeledo Perrot, 2012), p. 124.
} 


\section{LA NATURALEZA DEL MODO: ¿OBLIGACIÓN O CARGA?}

Aunque la doctrina no lo plantee en forma usual de esta manera, un extremo de relevancia para saber si estamos en presencia de una obligación, es la discusión relativa al sujeto activo. Para detenernos en esta polémica, haremos una breve síntesis de los planteamientos dogmáticos relativos al concepto de obligación y sus diferencias con la carga.

\section{Principales diferencias entre obligación, deber y carga}

Como sabemos, en la noción más clásica, se define obligación como "El vínculo jurídico entre personas determinadas, en virtud del cual una de ellas se encuentra en la necesidad de realizar una prestación en favor de la otra, que consiste en dar, hacer o no hacer algo" ${ }^{20}$. El deber jurídico, siguiendo a Puig Brutau, significa la necesidad de respetar las leyes, y de manera más determinada es la necesidad, impuesta por el ordenamiento jurídico, de observar determinado comportamiento frente a otras personas $^{21}$. De manera que todas las obligaciones son deberes jurídicos, pero no todos los deberes jurídicos son obligaciones, siendo en realidad la obligación sólo una especie de deber jurídico, el que existe entre acreedor y deudor ${ }^{22}$. Así lo expresa de los Mozos: "La obligación que es estudio del

${ }^{20}$ Esta noción clásica viene del Derecho romano, VINO, Arnoldo, Comentario académico y forense a los cuatros libros de las Instituciones Imperiales de Justiniano (Barcelona, Establecimientos tipográficos de D. Juan Oliveres. Impresor de S. M., 1847), II, p. 108. Así también lo explica de los Mozos: "En el segundo de los sentidos indicados, se denomina obligación (obligatio), ya desde el Derecho romano clásico, o aún preclásico, a una 'relación jurídica' por la que una persona, llamada acreedor, tiene derecho a exigir de otra, llamada deudor, una determinada prestación, hallándose amparado el derecho subjetivo que nace de esta relación por una acción personal (actio in personam)". Agrega el nombrado autor: "De acuerdo con esta precisión, la tradición pandectista coloca a las obligaciones entre los derechos personales, por contraposición a los derechos reales, viniendo de este modo a constituir una de las categorías más importantes de los derechos patrimoniales, y, por supuesto, el elemento básico de todo tráfico jurídico", DE LOs Mozos, José Luis, Concepto de obligación, en Revista de Derecho Privado (1980), p. 980.

${ }^{21}$ Puig Brutau, José, Fundamentos de Derecho Civil. Derecho general de las obligaciones (Barcelona, Editorial Bosch,1988), I/2, p. 5. En igual sentido, DíEz-PiCAzo, Luis, Fundamentos de Derecho Civil Patrimonial. Las relaciones obligatorias (Madrid, Civitas, 1996), III, p. 47.

${ }^{22}$ La obligación en sentido técnico abarca o comprende deberes jurídicos, pero no todos los deberes jurídicos. Hay deberes impuestos sobre todas las personas para que respeten determinados derechos: los derechos de la personalidad y los derechos reales. No integran, pues, el concepto de obligación en sentido técnico, estos deberes conjuntos o colectivos, que se difunden por el anonimato de sus titulares y que en 
Derecho de obligaciones es algo más que un deber jurídico, porque todas las obligaciones son deberes jurídicos, pero no todos los deberes jurídicos son obligaciones, y cuando hablamos de obligación nos referimos a una clase de deber jurídico, el que existe entre acreedor y deudor...Pero en todos estos casos para que haya obligación en sentido técnico, el deber que asume una de las partes (obligación, deuda) ha de corresponder al derecho de la otra (crédito), con independencia de que las partes se hallen ligadas específicamente en relación con la obligación de que se trate"23. En suma, existe una relación de género a especie, siendo los deberes jurídicos el primero, y la obligación, la segunda.

Aún definiciones más modernas, como la de Rodríguez Grez, plantean la cuestión exclusivamente desde la óptica del deudor. En efecto, el mencionado autor concibe la obligación como un deber de conducta tipificado en la ley. Este autor atiende al concepto de tipicidad que regula y rige el Derecho penal, y en consecuencia estima que el sujeto pasivo tiene el deber impuesto en forma coercitiva por la ley de desarrollar una prestación a favor de otro, cuando realiza (se verifica), una hipótesis expresamente señalada en la ley. De allí que afirma que es la ley la única fuente de las obligaciones, toda vez que es ella quien describe las hipótesis. Así, este autor señala: "Toda obligación impone siempre al sujeto pasivo o deudor el deber de comportarse de una manera determinada en beneficio del sujeto activo o pretensor. Este comportamiento está descrito en la ley, la cual establece, en cada caso, precisamente, que grado de diligencia, cuidado y atención debe poner el deudor en el desarrollo de la conducta que se ha comprometido o le es exigible (...) la norma consagra una hipótesis (descriptiva,), de la cual se sigue una consecuencia (prescriptiva). La obligación consiste precisamente, en la realización de aquella consecuencia ordenada en la ley y que se hace exigible luego de la producción del hecho descrito como hipótesis (el cual corresponde a la fuente de la obligación). En suma la ley (norma) ordena imperativamente que a la producción de una hipótesis (un hecho del hombre o de la naturaleza) se siga un deber de conducta que debe desplegarse, como se dijo, de la manera descrita en ella" ${ }^{24}$.

Como hemos visto, tradicionalmente la obligación se entiende como

doctrina se conocen sugestivamente con el nombre de "obligación pasiva universal". En este sentido se ha pronunciado RIBEIRO DE FARIA, Jorge Leite, Direito das obrigaçòes (Coimbra, Editorial Almedina, 1998), I, p. 26,

${ }^{23}$ De los Mozos, cit. (n. 20), pp. 981-982.

${ }^{24}$ Rodríguez Grez, Pablo, Responsabilidad contractual (Santiago, Editorial Jurídica de Chile, 2003), p. 10. El concepto, sin embargo, lo formuló en su libro $L a$ obligación como deber de conducta típica. La teoría de la imprevisión en Chile (Santiago, Universidad de Chile, 1992). 
la contrapartida de un derecho personal de crédito de un sujeto que se denomina acreedor. De Almeida advierte que corresponde a la orientación clásica, la perspectiva de la obligación que se agota en el deber de prestar y en su correlativo derecho de exigir o pretender una prestación. No obstante, al examinar la estructura de la relación obligatoria, se suele señalar cómo dentro de esta estructura existe siempre un elemento subjetivo, formado por los sujetos de la relación, que son, como es sabido, un sujeto activo o acreedor, que es la persona titular del poder jurídico de exigir la prestación, y un sujeto pasivo o deudor, sobre quien pesa el deber jurídico de realizar esta prestación; un elemento objetivo u objeto de la relación, consistente en aquella actividad o comportamiento que el sujeto pasivo tiene que desplegar en favor del sujeto activo, a la que se denomina técnicamente con el nombre de "prestación", y, finalmente, un vínculo jurídico entre ambos sujetos, por virtud del cual el deudor queda ligado con el acreedor. Es el vínculo jurídico el elemento sustancial de la relación obligatoria ${ }^{25}$.

Como indica Díez-Picazo, la idea de que en las relaciones obligatorias existe un vínculo jurídico es una idea extraordinariamente antigua. Aparece ya en las fuentes romanas, donde precisamente, una clásica y conocidísima definición caracteriza a la "obligatio" como un "vinculum iuris". La misma idea del vínculo jurídico ha reaparecido con perfecta nitidez en la doctrina moderna ${ }^{26}$. El elemento central y más propiamente de derecho de la obligación señalan los autores, está constituido por el vínculo jurídico, en virtud del cual el deudor queda ligado con el acreedor y obligado a satisfacerle una determinada prestación ${ }^{27}$.

zSegún Díez-Picazo, dibujado tan vagamente, el vínculo jurídico es algo que se distingue muy difícilmente de la misma relación obligatoria, hasta el punto de que relación obligatoria y vínculo jurídico parecen ser conceptos llamados a confundirse, es decir, parecen ser una misma cosa. La relación obligatoria es, siempre a juicio de Díez-Picazo, la total relación jurídica que liga a los sujetos para la realización de una determinada función económica

${ }^{25}$ De Almeida Costa, Mário Júlio, Direito das obrigaçòes (Coimbra, Almedina, 1991).

${ }^{26}$ Díez-Picazo, Luis, El contenido de la relación obligatoria, en Anuario de Derecho Civil 12 (1964), pp. 349 ss.

${ }^{27}$ Así, por ejemplo, Puig Ferrol indica: "Esta relación jurídica que pone en relación la obligación de realizar un determinado comportamiento y el derecho a exigirlo se denomina vínculo jurídico, que desde la perspectiva del deudor implica el deber de tener que dar o entregar alguna cosa, prestar algún servicio o actividad, o abstenerse de realizar algo que podría realizar de no haber contraido la obligación negativa de no hacer"; PUIG Ferrol, Luis - Gete Alonso y Calera, María - Gil Rodríguez, Jacinto - Hual de SÁnchez, José Javier, Manual de Derecho Civil. Derecho de obligaciones. Responsabilidad civil. Teoría general del contrato (Madrid, Marcial Pons, 1998), p. 20. 
o social en torno a un interés protegido por el ordenamiento jurídico ${ }^{28}$. La relación obligatoria es, conceptualmente, una relación jurídica de unas determinadas características técnicas, que la hacen diferenciarse del resto de las relaciones jurídicas de naturaleza patrimonial y, por supuesto, de todas las demás relaciones jurídicas de Derecho privado ${ }^{29}$.

Esta contraposición -crédito y deuda- suele parecer a primera vista muy clara: el crédito es, se suele decir, un derecho subjetivo y la deuda un deber jurídico. Los análisis de los autores de la naturaleza del vínculo jurídico sólo abordan esta perspectiva más clásica, es decir, considerando el crédito como puro derecho subjetivo y deuda como deber jurídico, según hemos analizado. Así, siguiendo a Fueyo, hay tres teorías que explican dicha última naturaleza ${ }^{30}$.

La teoría clásica fue elaborada por Savigny, para quien la persona del deudor puede estar sujeta a la voluntad, al señorío o dominio del acreedor, pero no se trata de un dominio absoluto o pleno sobre otro ser humano, porque, en ese caso, desaparecen los principios de libertad y dignidad del hombre. Al respecto, el profesor Fueyo indica: "Pero si concebimos una relación jurídica especial, consistente en el dominio sobre una persona ajena, sin destruir por completo su libertad, un derecho semejante al de propiedad pero que se distinga de él, debemos referir dicho dominio a una acción determinada de esa persona"31. A esa relación de dominio Savigny denomina "obligación” y la define como: "La relación de derecho por cuya virtud ejercemos un dominio sobre un determinado acto de otra persona" 32 .

Por último, la doctrina alemana ha desarrollado la teoría de la deuda y la responsabilidad, que expresa los dos momentos de la obligación. Siguiendo siempre a Fueyo, esta doctrina distingue entre una relación de débito entre los sujetos (debitum, Schuld) y una relación de responsabilidad (entendida como garantía patrimonial), entre el acreedor y los bienes del

${ }^{28}$ Díez-Picazo, cit. (n. 26), p. 350.

${ }^{29}$ Lacruz Berdejo concuerda con esta opinión y explica: "En la acepción más estricta y técnica del concepto, la última diferencia que individualiza a la obligación dentro del género deber jurídico, consiste en expresar por sí sola la total relación existente entre los sujetos que vincula...", Lacruz Berdejo, José, Sancho Rebullida, Francisco, luna Serrano, Agustín - Delgado Echeverría, Jesús - Rivera HerNÁNDEZ, Francisco - Rams Albesa, Joaquín, Elementos de Derecho Civil. Derecho de obligaciones. Parte general: Teoría general del contrato (Madrid, Editorial Dikynson, 1999), II/1, p. 3.

${ }^{30}$ Fueyo Laneri, Fernando, Cumplimiento e incumplimiento de las obligaciones (Santiago, Editorial Jurídica de Chile, 2001), pp. 31 ss.

${ }^{31}$ Ibid, p. 32.

${ }^{32}$ Von Savigny, Federico Carlos, Los fundamentos de la ciencia jurídica (Buenos Aires, Editorial Losada, 1949), p. 187. 
deudor susceptibles de ser perseguidos (obligatium, Haftung). El primer momento que hemos descrito está constituido por el deber de prestación del deudor, de naturaleza jurídica, porque la ley lo ha regulado especialmente y ha señalado su forma o pago. La segunda fase estaría constituida por la responsabilidad, la que, desde el punto de vista del deudor, significa sometimiento al poder de agresión, y desde el punto de vista del acreedor, es el derecho a accionar en contra de aquel que no ha dado cumplimiento a lo debido. Producido el incumplimiento, es decir, faltando el deber de prestación que corresponde a la primera fase, la agresión corresponde en contra del patrimonio, persiguiéndose el cumplimiento forzado en naturaleza, o bien, no siendo esto posible, demandándose el equivalente respectivo ${ }^{33}$.

Según Díez-Picazo, estas explicaciones parecen simples para ser exactas. Agrega que el crédito es, ante todo, una situación jurídica -la situación de crédito o la posición acreedora- donde confluyen facultades, pero donde convergen también cargas y acaso deberes. La deuda es otra situación jurídica -la situación de deuda o la posición deudora- en la que convergen fundamentalmente deberes, pero también hay facultades ${ }^{34}$. De Almeida explica que la doctrina moderna, sobretodo por mérito de los autores alemanes, evidenció la restricción del concepto clásico y la necesidad de superarlo. Y así, en una comprensión globalizadora de la relación obligatoria, aparecen, al lado de los deberes de prestación -tanto el deber principal como deberes secundarios, derechos potestativos, onus, expectativas, etc., que se coligan en relación a una finalidad y constituyen una relación compleja, de carácter unitario y funcional ${ }^{35}$.

Adicionalmente, la doctrina más moderna ha entendido que para el acreedor el crédito representa cargas y acaso deberes. En efecto, es necesario que el acreedor colabore con el deudor, en la medida que dicha colaboración sea necesaria, a objeto de que la prestación sea rectamente cumplida. La mayoría de los autores consideran que la colaboración que debe prestar el acreedor para que el deudor pague son meras cargas y no auténticos deberes jurídicos. Al respecto, el profesor Díez-Picazo indica:

${ }^{33}$ Fueyo Laneri,. (n. 30), pp. 34-40.

${ }^{34}$ Díez-Picazo, cit. (n. 25), p. 351. Concuerda con esta idea el profesor Fueyo, quien define la obligación como: "una relación de derecho entre dos o más personas, en cuya virtud una parte tiene el deber jurídico de satisfacer una prestación determinada a favor de otra, a la vez que el derecho a que el poder del acreedor no se exceda de sus límites, y a ser liberada al tiempo del cumplimiento, y la otra parte la facultad de exigir tal prestación, aún coercitivamente, a la vez que el deber de no excederse en su pretensión”, FueYo, cit. (n. 30), p. 21.

${ }^{35}$ De Almeida Costa, cit. (n. 25), p. 54. 
"En los casos que hemos examinado hay, en rigor "cargas" del acreedor y no auténticos deberes. No se trata de una conducta debida que otro pueda exigir, sino de una conducta necesaria sólo como requisito previo o como presupuesto del acto de ejercicio (...) No se trata de un auténtico "deber", sino de un 'tener que' para poder hacer. Sobre el acreedor como tal no recaen auténticos deberes. El deber presupone una correlativa facultad de exigir en otro y, por tanto en nuestro terreno, una deuda, es decir, de otro vínculo jurídico dentro de la misma relación obligatoria"36.

Luego, la doctrina afirma que hay una carga para el acreedor en el puntual y diligente examen de la prestación ya realizada, entre otras. En esta materia, Puig Ferrol indica: "Esta categoría jurídica de los deberes de comportamiento, que es uno de los elementos de la relación jurídica en general, cuando se proyecta sobre las relaciones obligatorias recibe comúnmente entre nosotros la denominación de cargas, o más concretamente, de cargas del acreedor" 37 .

La diferencia entre carga y deber radica en los intereses en juego: si se afecta un interés ajeno, podemos hablar técnicamente de deber, que puede integrar o no una relación obligatoria. Si, en cambio, se resguarda un interés propio, estamos en presencia del concepto de carga. La idea que el modo obedece a una carga tiene una connotación distinta, como analizaremos en breve. Estamos en presencia de un gravamen, antes que, de la necesidad de desarrollar una conducta en propio favor, pero ambos conceptos se encuentran en el caso que el modo resulta a favor del propio beneficiario.

\section{Por regla general el modo es una obligación}

Como hemos advertido, la doctrina discute la naturaleza del modo a propósito del sujeto activo o beneficiario con dicha modalidad. Rodríguez Grez considera que siempre debe haber un beneficiario que, en caso de ser un tercero, da lugar a los efectos propios de incumplimiento obligacional: "Cuando el modo se impone en beneficio de un tercero, el asignatario está obligado jurídicamente y su incumplimiento puede provocar o la resolución de la asignación (cuando hay cláusula resolutoria y el beneficiado opta por este camino) o la ejecución forzada de la obligación con indemnización de perjuicios" 38 .

${ }^{36}$ Díez-Picazo, cit. (n. 26), p. 359.

${ }^{37}$ Puig Ferrol, cit. (n. 27), p. 62.

${ }^{38}$ Rodríguez Grez, Pablo, Instituciones de Derecho sucesorio (Santiago, Editorial Jurídica de Chile, 2006), I, pp. 187-188. En el mismo sentido, Domínguez Benavente, Ramón y Domínguez Águila, Ramón, Derecho Sucesorio (Santiago, Editorial Jurídica de Chile, 1990), p. 471. 
Concretamente, y considerando todo lo señalado en forma precedente, en relación con el problema de la naturaleza del modo, Rodríguez Grez considera que siempre estamos en presencia, técnicamente, de una auténtica obligación, pero le reconoce algunas características propias: la obligación impuesta por el modo no nace sino una vez aceptada la asignación; la cláusula resolutoria hace que opere una verdadera condición resolutoria tácita; en ausencia de cláusula resolutoria, sólo puede pedirse el cumplimiento forzado; y si el modo ha sido establecido a favor del propio asignatario, no hay obligación. Para Rodríguez, el modo deviene en este caso en condición resolutoria simplemente potestativa, encontrándose expuesto a perder la asignación si hay cláusula resolutoria; no puede haber asignación modal a favor de personas indeterminadas y, en caso de que la asignación sea dada a favor de sujeto indeterminado, el silencio del testador lo suple la ley (artículo 1056 del Código civil), otorgando una acción general ${ }^{39}$. Una opinión distinta sostiene Elorriaga, quien considera que no estamos frente a una obligación como ésta se la conoce en la teoría general, por cuanto admite que el beneficiario pueda estar indeterminado ${ }^{40}$.

A nuestro juicio, no puede caber duda alguna que el modo constituye una obligación, técnicamente configurada, cuando el beneficiario es un tercero. Hay dos órdenes de argumentos.

En primer lugar, hay argumentos de texto: el esquema de los legados sujetos a modo es aplicable a las obligaciones modales, conforme al artículo 1493 del Código civil y corresponde su aplicación a las fuentes de las obligaciones, según se ha examinado. Las mismas normas se aplican a las donaciones, conforme al artículo 1405 del Código Civil. En fin, los artículos 1092 y 1096 del Código de Bello destacan las características esenciales de la obligación: sujetos, activo y pasivo, un vínculo jurídico que los constriñe y como objeto, una prestación.

En segundo término, la regulación de las herramientas de tutela, a favor del acreedor, son propias del régimen de incumplimiento obligacional. En esta materia el Código ha sido particularmente claro y la doctrina está de acuerdo en que las acciones disponibles son las de resolución (en caso de existir cláusula resolutoria) o cumplimiento forzado. Pero no puede existir duda cuando se atiende al régimen de incumplimiento de las donaciones modales, conforme a lo prescrito en el artículo 1426 del Código civil.

Si se asume, por lo tanto, que estamos en presencia de una obligación, técnicamente configurada, no puede admitirse la existencia de un sujeto activo o beneficiario indeterminado. En esta materia, compartimos la opi-

${ }^{39}$ Rodríguez Grez, Pablo, cit. (n. 38), pp. 187-189.
${ }^{40}$ Elorriaga de Bonis, Fabián, cit. (n. 6), p. 295. 
nión del profesor Rodríguez Grez, antes analizada. Si el modo puede ser considerado una carga, lo es en un sentido impropio, como sinónimo de gravamen y, en este sentido, de garantía en sentido amplio. El concepto de garantía es complejo, pues, como sucede frecuentemente con toda noción jurídica, éste no es unívoco. En un sentido amplísimo, comprende todos los mecanismos de tutela del crédito, de ahí que existan dificultades para determinar su contenido ${ }^{41}$. Según Roca i Trías: "la garantía está concebida como un sistema de aseguramiento, legal o voluntario, cuya finalidad esencial es preservar el interés del acreedor, asegurando el cumplimiento de la prestación”. Por eso, en un sentido amplio, el concepto garantía comprende también unos mecanismos cuya finalidad es también el aseguramiento del derecho del crédito, pero que no pueden ser consideradas garantías en sentido técnico ${ }^{42}$.

Otro aspecto de relevancia para nuestra investigación se refiere a la situación en la que el modo ha sido establecido a favor del propio asignatario o donatario, según los casos. No puede haber aquí, en sentido técnico una obligación. Ya hemos visto que, conforme a lo prescrito en el artículo 1092, el modo no puede ser exigido, salvo que envuelva cláusula resolutoria. En este sentido, en ausencia de acreedor, compartimos la opinión del profesor Rodríguez Grez, en orden a que opera aquí, lisa y llanamente, una condición resolutoria.

\section{IV. ¿EXISTE UNA OBLIGACIÓN MODAL EN LA LEY No 13.080?}

En esta parte del trabajo centraremos nuestro interés en el estudio de la Ley No 13.080 . Se trata de una ley que no cumple con dos de las características más propias de la ley, como es su generalidad y abstracción ${ }^{43}$. Como lo ha explicado Ducci, la ley se establece "para un número indeterminado de actos o hechos, o para que rija a todas las personas que se encuentran

\footnotetext{
${ }^{41}$ Se ha afirmado que: "Esta materia es buen ejemplo que el Derecho es eminentemente lenguaje, con rica y plurívoca terminología, cuyas voces son empleadas con variante significado por cuatro grandes coros hasta hoy faltos de batuta que los coordine: el de los contratantes en la práctica, el de la doctrina, el de la jurisprudencia y el de los legisladores", VICENT CHULIÁ, Francisco, Introducción al estudio de las garantías personales en el Ordenamiento español, en VV.AA., Tratado de garantías en la contratación mercantil. Parte General y garantías personales (Madrid, Civitas, 1996), I, p. 37.

${ }^{42}$ Roca I TRÍAs, Encarna, Rasgos básicos de la regulación española en materia de negocios de garantía, en VV.AA., Tratado de garantías en la contratación mercantil. Parte general y garantías personales (Madrid, Civitas, 1996), I, pp. 134-135.

${ }^{43}$ Otro ejemplo de leyes excepcionales en el sentido indicado son las que conceden o privan de la nacionalidad concedida por gracia.
} 
en una situación determinada" ${ }^{44}$. Teniendo en vista lo anterior, la generalidad se basa en la igualdad ante la ley. En razón de su generalidad, la ley deviene en abstracta: en este sentido, las leyes "no prevén casos concretos, sino situaciones-tipo" ${ }^{45}$.

Por el contrario, la aludida norma tiene un destinatario específico: el Club Hípico de Antofagasta. Lo planteado se entiende al considerar que la Ley No 13.080 es una ley expropiatoria de terrenos que pertenecían a la mencionada persona jurídica y como contrapartida, se le adjudican ciertos terrenos.

Primero analizaremos el texto de la ley para poder sostener la presencia de un modo y, a continuación, las características de esta modalidad legal.

\section{Modo establecido por la Ley $N^{\circ} 13.080$}

La Ley No 13.080 fue publicada en el Diario Oficial el 5 de noviembre de 1958. Consta de seis artículos, que analizaremos someramente. El artículo 1 fija el objeto primordial de la Ley, a saber, autorizar a la Ilustre Municipalidad de Antofagasta a expropiar unos terrenos que, emplazados en el actual Estadio Regional, se consideraron, bien por su ubicación estratégica, bien por las necesidades que traería aparejada la celebración de la Copa del Mundo, Chile 1962, como de utilidad pública.

Así, el referido artículo 1 dispuso: "Declárase de utilidad pública y autorízase a la Municipalidad de Antofagasta para expropiar el terreno de propiedad del Club Hipico de Antofagasta, ubicado en la calle Avenida Angamos, de la ciudad de Antofagasta, con una superficie de 152.680 metros cuadrados y que tiene los siguientes deslindes, (...) La expropiación se ajustará a las normas establecidas en el Título XV del Libro IV del Código de Procedimiento Civil. El terreno individualizado en este artículo se destinará a la construcción del Estadio Regional de Antofagasta, según los planos y en la extensión que señale el Departamento de Arquitectura del Ministerio de Obras Públicas".

Como mecanismo de compensación (no en sentido técnico, desde luego), se estableció a favor del Club Hípico de Antofagasta, la donación de los terrenos ubicados en el sector denominado "La Chimba". Particularmente, el artículo 2, que es el que nos interesa, estableció: "Autorizase al Presidente de la República para conceder, al Club Hipico de Antofagasta, a titulo gratuito de dominio de los terrenos fiscales entregados en arrendamiento a esa institución, en la localidad de La Chimba, departamento y comuna de

${ }^{44}$ Ducci Claro, Carlos, Derecho civil. Parte general (4a edición, Santiago, Editorial Jurídica de Chile, 2005), p. 44.

${ }^{45}$ Alessandri Rodríguez, Arturo - Somarriva Undurraga, Manuel - VodaNovic H., Antonio, Tratado de Derecho civil. Partes preliminar y general (Santiago, Editorial Jurídica de Chile, 2015), I, p. 32. 
Antofagasta, según resolución 120, de 10 de julio de 1956, del Departamento de Bienes Nacionales del Ministerio de Tierras y Colonización (...)". Agrega el inciso 2 de la misma disposición que: "El Club Hipico de Antofagasta destinará estos terrenos a la construcción del nuevo hipódromo, con los edificios e instalaciones anexos, construcción que deberá hacerse en el plazo de tres años, contados desde que se otorgue el título gratuito de dominio a que se refiere el inciso anterior y se efectúe el pago efectivo del valor de la expropiación a que se refiere el artículo $1^{\circ}$ ".

El artículo 3 reguló la cesión de terrenos adicionales a favor de la Ilustre Municipalidad de Antofagasta. Por su parte, el artículo 4 prescribió el mecanismo de pago de las expropiaciones, mientras que el artículo quinto autorizó a la Municipalidad de Antofagasta a expropiar parte de los terrenos. Finalmente, el artículo 6 declaró exentas de toda clase de impuestos las transferencias de bienes raíces realizadas en conformidad a lo establecido en los artículos 1, 2, 3 y 5. Podemos advertir que no se ha establecido en el cuerpo de la ley ninguna cláusula resolutoria, este es un aspecto fundamental para determinar las consecuencias que nacerían de un eventual incumplimiento del modo.

Como ya hemos indicado, la disposición sobre la que se centra nuestro interés es el artículo 2, inciso 2 de la ley en comento, que según se ha señalado, establece que el Club Hípico de Antofagasta debe destinar ciertos terrenos a la construcción de un nuevo hipódromo, dentro del plazo de tres años, sin consignarse en la norma las consecuencias jurídicas de la falta de cumplimiento dentro del plazo establecido. Teniendo presente lo sostenido, pensamos que en este artículo el legislador estableció un modo. A mayor detalle, la conclusión indicada en el párrafo precedente se ve ratificada si analizamos las definiciones de modo, tanto la establecida por el legislador como la comúnmente mencionada en doctrina. En este sentido, la definición legal de modo se encuentra contenida en el artículo 1089 del Código Civil, en cuya virtud: "Si se asigna algo a una persona para que lo tenga por suyo con la obligación de aplicarlo a un fin especial, como el de hacer ciertas obras o sujetarse a ciertas cargas, esta aplicación es un modo y no una condición suspensiva. El modo, por consiguiente, no suspende la adquisición de la cosa asignada". Se suele citar la definición de modo de Somarriva, para quien dicha modalidad consiste en "la carga que se impone a quien se otorga una liberalidad"46.

Continuando en la senda trazada en las líneas anteriores, analizando, en primer término, el artículo 1089, queda claro que la noción legal de modo se compone de dos elementos. Tales son, la asignación de algo a

\footnotetext{
${ }^{46}$ Somarriva, cit. (n. 18), p. 290.
} 
una persona para que lo tenga por suyo y la obligación de destinarlo a un fin especial. Ambos elementos concurren a propósito del modo creado por la Ley No 13.080. Así, el inciso 20 del artículo 2 de dicha Ley, por una parte, asigna en propiedad a la persona jurídica Club Hípico de Antofagasta ciertos terrenos y, por otra parte, obliga a éste a un fin especial, concretado en la construcción dentro de cierto plazo del nuevo hipódromo de la ciudad de Antofagasta. Razonando ahora sobre la definición de Somarriva, también arribamos a la conclusión de que la Ley No 13.080 ha establecido un modo. Efectivamente, sin perjuicio de lo comentado en este trabajo sobre la noción de "carga", el Estado de Chile ha realizado una liberalidad, una donación, en favor del Club Hípico de Antofagasta, persona jurídica que como ya se ha repetido debía realizar la construcción de un nuevo hipódromo. Además, debe admitirse otro extremo, a saber, la aplicabilidad al modo establecido en la Ley No 13.080 de las normas no sólo de las asignaciones testamentarias modales y obligaciones modales, sino de aquellas relativas a las donaciones irrevocables. En estos casos procede la aludida aplicación en todo aquello que no pugne con la donación hecha por vía legal. Por ejemplo, resulta evidente que no puede exigirse escritura pública o el trámite de la insinuación. En lo demás, no vemos inconveniente en aplicar las normas del Código civil, que para los efectos es Derecho común y, por tanto, supletorio.

Especialmente debe acordarse esta conclusión, toda vez que la Ley No 13.080 ordena conceder, a título gratuito, los terrenos ubicados en el sector denominado "La Chimba", lo que finalmente se concreta en virtud del Decreto No 1425, de 19 de octubre de 1960, cuerpo normativo que se redujo a escritura pública el 21 de septiembre de 1962. Aquí operó además la aceptación de la donación ${ }^{47}$.

Todo lo señalado en los párrafos precedentes fue declarado judicialmente. Así, el establecimiento por parte de la Ley No 13.080 de una obligación de un modo fue reconocido en la sentencia Rol No 480-2017, caratulada "Zanabria con Club Hípico de Antofagasta S.A.", de fecha 5 de julio de 2018, dictada por la Corte de Apelaciones de Antofagasta ${ }^{48}$. En efecto, en el considerando séptimo de la individualizada sentencia se declaró lo siguiente: "Que en relación al primer agravio alegado por los demandantes apelantes, esto es, el no diferenciar jurídicamente la condición del modo, el mismo resulta irrelevante toda vez que la controversia de esta causa no radica en diferenciarlo, pues existe consenso entre las partes que el Fisco donó los te-

${ }^{47} \mathrm{La}$ correspondiente escritura fue inscrita a fojas 623 vta., número 1177 del Registro de Propiedad del año 1962, del Conservador de Bienes Raíces de Antofagasta.

${ }^{48}$ Disponible en www.pjud.cl, fecha de última visita: 07 de agosto de 2018. 
rrenos de autos, para destinarlos a construir en el mismo, el nuevo hipódromo de Antofagasta, lo que permite concluir que dicha donación fue modal'.

\section{Caracterización de la obligación modal creada por el inciso 2 del artículo} 2 de la Ley $N^{o} 13.080$

Partiendo del supuesto de aplicabilidad de las normas sobre las asignaciones testamentarias modales, las obligaciones modales y las donaciones modales, pueden analizarse las características del modo legal en análisis $y$, sobre dicha base, los efectos derivados de su incumplimiento. El modo que comentamos presenta, en nuestra opinión, las siguientes notas ${ }^{49}$ : el gravamen impuesto no es permanente (pronto explicaremos la relevancia práctica que tuvo esta característica); coinciden en una misma persona el asignatario modal y el beneficiado con el modo; y, en caso de incumplimiento, no procede la resolución.

a) El gravamen no es permanente. Consideramos que la Ley No 13.080 establece simplemente un modo y que no sujeta permanentemente a un gravamen al Club Hípico de Antofagasta. Comencemos con la redacción del precepto. El artículo 2 emplea la siguiente expresión: el Club Hípico de Antofagasta destinará los corrzespondientes terrenos a la construcción de un hipódromo, lo que deberá hacerse en el plazo de tres años, contados desde que: "a) se otorgue el titulo gratuito de dominio a que se refiere el inciso anterior; b) y se efectúe el pago efectivo del valor de la expropiación a que se refiere el artículo $10^{\prime \prime}$.

El verbo "destinar", de acuerdo con la Real Academia Española de la Lengua, significa "ordenar, señalar o determinar algo para algún fin o efecto". El hecho que el verbo se use en el indicativo futuro "destinara”" y no en el subjuntivo “destinare”, es prueba gramatical de lo que viene señalándose. En efecto, para una mejor comprensión de la cuestión, no puede desconocerse el contexto de la Ley No 13.080. El objetivo principal de dicha normativa fue la expropiación de los terrenos del Club Hípico de Antofagasta para poder construir en tales terrenos el actual Estadio Regional de la mencionada ciudad. La donación fue una consecuencia de dicha expropiación. Ello explica a nuestro juicio, dos cuestiones:

- Que el modo se limite a exigir (destinará dice la norma) la construcción

\footnotetext{
${ }^{49}$ Recordemos que el modo como modalidad de las asignaciones testamentarias presenta las siguientes características: al fallecer el causante se adquiere la asignación, esto es, a diferencia de la condición suspensiva, el modo no suspende la adquisición del derecho; y el modo es transmisible en el supuesto del artículo 1095: "Si el modo consiste en un hecho tal, que para el fin que el testador se haya propuesto sea indiferente la persona que lo ejecute, es transmisible a los herederos del asignatario".
} 
de un hipódromo y no la dedicación exclusiva, excluyente, permanente o perpetua a alguna actividad;

- Que se señale un plazo para el cumplimiento de la destinación (tres años). La Ley No 13.080 dispuso que el plazo se contaba, como se ha advertido, desde el otorgamiento del título de donación y desde que se pagase la indemnización correspondiente a la expropiación. Lógicamente, se contaba con que los dineros de la expropiación fueran destinados a la construcción de un nuevo hipódromo.

Una vez verificado lo anterior, no se advierte por qué el Estado tendría que tener un interés en una actividad esencialmente privada, por mucho que ésta tenga repercusión en un sector de la comunidad. La cuestión estriba en determinar el uso del hipódromo. Estamos en presencia de una actividad privada, lucrativa, a la que concurren personas que se interesan por la actividad hípica. Se trata, en suma, de un régimen de apuesta especialmente regulado, que reporta utilidades.

Lo afirmado no obedece solamente a una pura apreciación. Esta es la óptica propia de la regulación de la Ley No 4.566, General de Hipódromos, de 5 de febrero de 1929, modificada por la Ley No 20.662, de 25 de abril de 2013. Conforme al artículo 1 de la referida ley: "Los hipódromos establecidos por autorización del Presidente de la República, y que pertenezcan a sociedades fundadas con el primordial objeto de mejorar las razas caballares y que obtengan personalidad jurídica de conformidad con las leyes, podrán organizar y mantener el sistema de las apuestas mutuas con arreglo a los reglamentos que se expidan por el Presidente de la República". Por su parte, el artículo 3 de la misma establece: "Las disposiciones de los artículos 277, 278, 279 del Código Penal se aplicarán a todo aquel que, en cualquier lugar, o bajo cualquier forma que sea, explote las apuestas de caballos, ya sea apostando, ya ofreciendo apostar, ya directamente, ya como intermediario con el público, sin que tenga esta prescripción otra excepción que la establecida en el artículo $1^{\circ}$ de esta ley". En el mismo sentido, el artículo 5 prescribe que: "Sólo quedan permitidas por esta ley las apuestas mutuas que se verifiquen dentro de los recintos de los hipódromos o en sus oficinas y dependencias, bajo la vigilancia directa de las instituciones hipicas legalmente autorizadas y con intervención del representante de la respectiva Junta de Beneficencia".

La anticipada relevancia práctica de esta característica puede apreciarse en la causa Rol 480-2017, a la que ya nos hemos referido con anterioridad. En este juicio, una vez transcurridos muchos años desde la construcción del nuevo hipódromo, Club Hípico de Antofagasta enajenó los terrenos que se le habían adjudicado en virtud de la Ley No 13.080, lo que motivó la alegación de nulidad absoluta de los correspondientes contratos de compraventa y, en subsidio, el cumplimiento del modo establecido en la 
citada ley. Todas estas alegaciones fueron desestimadas, y la Corte de Apelaciones de Antofagasta consideró que el modo legal en comento no era de carácter permanente ${ }^{50}$. Para lo último, se basó el sentenciador en la tutela constitucional otorgada al derecho de dominio, en la que se incluyen sus facultades, y en el respecto al principio de libre circulación de los bienes.

b) Coinciden en la misma persona el asignatario modal y el beneficiado. Se trata de un modo particular, puesto que, el asignatario modal es el Club Hípico de Antofagasta y, el beneficiado con el modo, esta misma persona jurídica. Efectivamente, los terrenos individualizados en la Ley No 13.080 son adjudicados en dominio al Club Hípico de Antofagasta, para que se destinen a la construcción de un nuevo hipódromo, lo que evidentemente, resulta en un considerable beneficio de índole pecuniaria en favor de la mencionada persona jurídica.

A mayor detalle, no se aprecia qué tercero podría ser el beneficiario con el modo. Ciertamente, toda actividad, con o sin fines de lucro, puede envolver beneficiarios indirectos. Pero en el modo, el sujeto activo, de haberlo, no puede ser indeterminado, ni reflejo. Ciertamente, no puede atribuirse esa calidad a los apostadores de carreras de caballos. En ausencia de sujeto activo determinado, no resulta posible pensar que estamos frente a una obligación, tal como se ha analizado latamente, lo que nos lleva a una tercera consideración: no puede haber modo que sujete al Club Hípico de Antofagasta, de no mediar la existencia de una cláusula resolutoria.

${ }^{50}$ En el considerando sexto de la sentencia se indicó que: "es conveniente analizar que la intención de los demandantes busca mantener incólume la obligación de la sociedad, en cuanto a mantener el hipódromo como carga o modo del terreno que representó la transferencia a título gratuito del Fisco, lo que resulta desde ya alejado al concepto del derecho de propiedad establecido en el artículo 582 del Código Civil y en la Constitución Política de la República, articulo $19 N^{\circ} 24$, en la medida que confiere la facultad de usar, gozar y disponer de ello solo con las limitaciones y obligaciones que deriven de una función social, en cuanto se exija por intereses generales de la nación, la seguridad nacional, la utilidad y salubridad públicas y conservación del patrimonio ambiental, allí mismo se establece que nadie puede en caso alguno ser privado de su propiedad, del bien sobre el que recae o de los atributos o facultades esenciales del dominio, sino en virtud general o especial que autorice la expropiación por causa de utilidad pública o de interés nacional, calificada por el legislador; ninguna de estas restricciones se ha alegado en la causa, lo que tampoco sería suficiente porque se requeriría una expropiación o una ley que estableciera permanentemente esta carga con la subsiguiente cláusula resolutoria, situación que ello no concurre y que por lo demás, ya lo hizo presente el Fisco de Chile en su documento de fojas 92 ". 
c) El incumplimiento del modo no genera como consecuencia la procedencia de la resolución. La tercera característica deriva de la anterior, de esta manera, en atención a lo señalado, cobra relevancia la aplicación de la norma contenida en el artículo 1092 del Código civil, esto es, si el modo cede en beneficio exclusivo del asignatario modal, no envuelve obligación alguna, a menos que exista cláusula resolutoria, lo que no acontece a propósito de la Ley No 13.080. Así, en el articulado de la mencionada Ley, al que ya nos hemos referido, en parte alguna se establece la procedencia de la resolución en el caso de incumplir el asignatario con el modo impuesto.

Con todo, en la sentencia que resolvió la causa Rol 480-2017 se estableció que no se incumplió el modo, dado que el Club Hípico de Antofagasta sí construyó, dentro del plazo correspondiente, un nuevo hipódromo para la ciudad de Antofagasta. Dicha conclusión no se ve afectada por la posterior enajenación de los terrenos respectivos. En este sentido, se indicó en el considerando décimo cuarto de la sentencia lo siguiente: "Ahora bien en este caso, la transferencia del bien raiz hecha por el Fisco al C.H.A., contenía el modo de efectuar la construcción detallada en el artículo $2^{\circ}$ de la ley 13.080, lo que se cumplió en el término fijado, cuestión que no ha resultado controvertida en esta causa, pues nada se alega en dicho sentido, máxime si se considera que los demandantes fundan su demanda en algo distinto a ello, al basar su acción en considerar como modo de la transferencia, el destino del terreno a la actividad hipica, cuestión que no resulta válida, como se concluyó en los considerandos sexto y noveno de esta sentencia".

Agréguese a lo indicado que, con respecto a la donación, la acción resolutoria procede en el caso en que el donatario estuviere en mora de cumplir lo que en la donación se le ha impuesto siempre que la condición conste expresamente en la escritura pública de la donación ${ }^{51}$. Lo último no ocurre en la Ley No 13.080, según hemos tenido oportunidad de analizar, ni en la donación que se concreta en razón de dicha Ley.

En definitiva, en el evento de incumplimiento del modo creado por la Ley No 13.080, solo cabría deducir la acción de cumplimiento forzado.

\section{Conclusiones}

En virtud del trabajo realizado, podemos llegar a las siguientes conclusiones:

1. El sistema de fuentes de obligaciones en el Derecho chileno, nos indica que se reconocen las cinco fuentes clásicas: los contratos, los cua-

${ }^{51} \mathrm{La}$ resolución de las donaciones se regula en los artículos 1424 a 1427 del Código civil. 
sicontratos, los delitos, los cuasidelitos y la ley. No recoge el sistema chileno, en su sistemática, la adopción de los actos unilaterales como fuente obligacional. La regulación de las asignaciones testamentarias modales nos permite concluir, que la ley puede prescribir y constituirse en fuente de obligaciones modales. Por la misma razón, no existe obstáculo, a nuestro juicio, para pensar que la Ley No 13.080 estableció directamente y es fuente, en consecuencia, de un modo, que necesariamente se incorpora al contrato de donación que autorizó.

2. Por otro lado, concluimos que también resultan aplicables en la materia las normas sobre las donaciones irrevocables, en todo aquello que no pugne con la donación hecha por vía legal. En lo demás, no vemos inconveniente de aplicar las normas del Código civil, que es Derecho común y, en consecuencia, supletorio.

3. Especialmente deben acordarse las indicadas conclusiones, puesto que la Ley No 13.080 ordena conceder, a título gratuito, los terrenos ubicados en la Chimba, lo que finalmente se concreta en virtud del Decreto No 1425, de 19 de octubre de 1960. Aquí operó, además la aceptación de la donación, con lo que no puede negarse el carácter convencional de la donación, escritura inscrita en el Registro de Propiedad del Conservador de Bienes Raíces de Antofagasta.

4. A nuestro juicio, no puede caber duda alguna que el modo constituye una obligación, técnicamente configurada, cuando el beneficiario es un tercero. Ello, en atención a una doble fundamentación. En primer lugar, en virtud de argumentos de texto: el esquema de los legados sujetos a modo es aplicable a las obligaciones modales, conforme a lo prescrito en el artículo 1493 y cabe su aplicación a las fuentes de las obligaciones. Las mismas normas se aplican a las donaciones, según el artículo 1405 del Código de Bello. Además, los artículos 1092 y 1096 destacan las características esenciales de la obligación: sujetos, activo y pasivo, un vínculo jurídico que los liga y una prestación.

En segundo término, la disciplina de las herramientas de tutela, establecida en favor del acreedor, son propias del régimen de incumplimiento obligacional. En esta materia el Código ha sido particularmente claro y la doctrina está de acuerdo en que las acciones disponibles en el modo son las de resolución (siempre que exista cláusula resolutoria) o cumplimiento forzado.

5. Si se asume, por lo tanto, que estamos en presencia de una obligación, técnicamente configurada, no puede admitirse la existencia de un sujeto activo o beneficiario indeterminado. Cuando el modo ha sido establecido a favor del propio beneficiario, no puede haber en dicho escenario, en sentido técnico, una obligación. Conforme a lo prescrito en el artículo 
1092 del Código civil, el modo no puede ser exigido, salvo que envuelva cláusula resolutoria.

6. Consideramos que la Ley No 13.080 contempla lisa y llanamente un modo no sujeto a gravamen permanente alguno. Los términos empleados por el legislador contribuyen a afirmar esta conclusión, en particular, en particular, la utilización de la palabra "destinará".

7. El modo establecido en la Ley No 13.080 se encuentra establecido en el solo beneficio del donatario. Asignatario modal y beneficiado coinciden. En efecto, no puede desconocerse el contexto de la mencionada Ley. El objeto principal de ella fue la expropiación de los terrenos del Club Hípico de Antofagasta y, como contrapartida, se adjudicaron otros terrenos en dominio al nombrado club, pero dicha adjudicación se encontraba sujeta a un modo, consistente en la construcción de un nuevo hipódromo. La donación fue una consecuencia de dicha expropiación. Ello explica que el modo se limite a exigir la construcción de un hipódromo y no la dedicación exclusiva, excluyente, permanente o perpetua a alguna actividad y que se señale un plazo para el cumplimiento de la destinación.

8. Finalmente, considerando la precedente conclusión, en el caso del modo establecido por la Ley No 13.080, en un supuesto de eventual incumplimiento, dado que no existe en la letra de la Ley cláusula resolutoria alguna, solo sería procedente el cumplimiento forzado del modo.

\section{Bibliografía}

Abeliuk Manasevic, René, Las obligaciones (Santiago, Editorial Jurídica de Chile, 2000), I.

Alessandri Rodríguez, Arturo, De la compraventa y de la promesa de venta (Santiago, Editorial Jurídica de Chile, 2003), I/1.

Alessandri Rodríguez, Arturo - Somarriva Undurraga, Manuel - Vodanovic H., Antonio, Tratado de Derecho civil. Partes preliminar y general (Santiago, Editorial Jurídica de Chile, 2015), I.

Alessandri Rodríguez, Arturo - Somarriva Undurraga, Manuel - Vodanovic H., Antonio, Tratado de los Derechos reales (6 edición, Santiago, Editorial Jurídica de Chile, 2001), I.

Alessandri Rodríguez, Arturo - Somarriva Undurraga, Manuel - Vodanovic H., Antonio, Tratado de las Obligaciones. De las obligaciones en general y sus diversas clases (2a edición ampliada, Santiago, Editorial Jurídica de Chile, 2000), I.

Arangio-Ruiz, Vicenzo, Istituzioni di Diritto Romano (14a edizione, Napoli, Casa Editrice Dott. Eugenio Jovene, 2012).

Claro Solar, Luis, Explicaciones de Derecho civil chileno y comparado (Santiago, Editorial Jurídica de Chile, 2015), V.

De Almeida Costa, Mário Júlio, Direito das obrigaçòes (Coimbra, Almedina, 1991). De los Mozos, José Luis, Concepto de obligación, en Revista de Derecho Privado (1980). 
Díez-Picazo, Luis, Fundamentos de Derecho Civil Patrimonial. Las relaciones obligatorias (Madrid, Civitas, 1996), II.

Díez-PiCAzo, Luis, El contenido de la relación obligatoria, en Anuario de Derecho Civil 12 (1964), pp. 349-366.

Domínguez Benavente, Ramón - Domínguez Águila, Ramón, Derecho Sucesorio (Santiago, Editorial Jurídica de Chile, 1990).

D'Ors, Álvaro, Derecho Privado Romano (9a edición, Pamplona, Ediciones Universidad de Navarra, 1997).

Ducci Claro, Carlos, Derecho civil. Parte general (4ª edición, Santiago, Editorial Jurídica de Chile, 2005).

Elorriaga de Bonis, Fabián, Derecho Sucesorio (Santiago, LexisNexis, 2005).

Floris Magadant, Guillermo, El Derecho Privado Romano (17a edición, Ciudad de México, Esfinge, 1991).

Fueyo Laneri, Fernando, Cumplimiento e incumplimiento de las obligaciones (Santiago, Editorial Jurídica de Chile, 2001).

García Garrido, Manuel, Derecho Privado Romano. Casos, acciones, instituciones (7a edición, Madrid, Editorial Dykinson, 1998).

Goldenberg Serrano, Juan Luis, Venta al peso, cuenta o medida y venta al gusto, en Contardo González, Juan Ignacio - De la Maza Gazmuri, Iñigo (dirs.), La compraventa. Estudios (Santiago, Thomson Reuters, 2017).

GuZmán Brito, Alejandro, Estudios sobre los legados según el Derecho civil chileno (Santiago, Abeledo Perrot, 2012).

Lacruz Berdejo, José z- Sancho Rebullida, Francisco - Luna Serrano, Agustín - Delgado Echeverría, Jesús - Rivera Hernández, Francisco - Rams Albesa, Joaquín, Elementos de Derecho Civil. Derecho de obligaciones. Parte general: Teoría general del contrato (Madrid, Editorial Dikynson, 1999), II/1.

LEÓn HurTADO, Avelino, La voluntad y la capacidad en los actos jurídicos (reimpresión de la $3^{a}$ edición, Santiago, Editorial Jurídica de Chile, 1990).

Morales Moreno, Antonio Manuel, El propósito práctico y la idea de negocio jurídico en Federico de Castro, en el mismo, Modernización del Derecho de obligaciones (Madrid, Thomson Civitas, 2006).

Peñailillo Arévalo, Daniel, Las obligaciones. Teoría general y clasificaciones. La resolución por incumplimiento (Santiago, Editorial Jurídica de Chile, 2003).

Peñailillo Arévalo, Daniel, Los bienes. La propiedad y otros derechos reales (3a edición, Santiago, Editorial Jurídica de Chile, 2002).

Puig Brutau, José, Fundamentos de Derecho Civil. Derecho general de las obligaciones (Barcelona, Editorial Bosch,1988), I/2.

Puig Ferrol, Luis - Gete Alonso - Calera, María - Gil Rodríguez, Jacinto Hual de Sánchez, José Javier, Manual de Derecho Civil. Derecho de obligaciones. Responsabilidad civil. Teoría general del contrato (Madrid, Marcial Pons, 1998).

Ribeiro DE FARIA, Jorge Leite, Direito das obrigaçòes (Coimbra, Editorial Almedina, 1998), I.

ROCA I TRÍAs, Encarna, Rasgos básicos de la regulación española en materia de negocios de garantía, en VV.AA., Tratado de garantías en la contratación mercantil. Parte general y garantías personales (Madrid, Civitas, 1996), I.

Rodríguez Grez, Pablo, Instituciones de Derecho sucesorio (Santiago, Editorial Jurídica de Chile, 2006), I. 
Rodríguez Grez, Pablo, Responsabilidad contractual (Santiago, Editorial Jurídica de Chile, 2003).

Rodríguez Grez, Pablo, La obligación como deber de conducta típica. La teoría de la imprevisión en Chile (Santiago, Universidad de Chile, 1992).

Silva Segura, Enrique, Acciones, actos y contratos sobre cuotas (Santiago, Editorial Jurídica de Chile, 1985).

Somarriva Undurraga, Manuel, Indivisión y partición (reimpresión de la $5^{\mathrm{a}}$ edición, actualizada por Gonzalo Figueroa Yáñez, Santiago, Editorial Jurídica de Chile, 2006).

Somarriva Undurraga, Manuel, Derecho Sucesorio (7a edición actualizada, versión de René Abeliuk, Santiago, Editorial Jurídica de Chile, 2005).

VICENT Chuliá, Francisco, Introducción al estudio de las garantias personales en el ordenamiento español, en VV.AA., Tratado de garantías en la contratación mercantil. Parte general y garantías personales (Madrid, Civitas, 1996), I.

Vidal Olivares, Álvaro, La noción de incumplimiento esencial en el Código Civil, en Revista de Derecho de la Pontificia Universidad Católica de Valparaiso 32 (2009).

VINO, Arnoldo, Comentario académico y forense a los cuatros libros de las Instituciones Imperiales de Justiniano (Barcelona, Establecimientos tipográficos de D. Juan Oliveres. Impresor de S. M., 1847), II.

Vodanovich H., Antonio, Manual de Derecho Civil. Parte preliminar y general (Santiago, Editorial Conosur, 2001).

Von SAvigny, Federico Carlos, Los fundamentos de la ciencia jurídica (Buenos Aires, Editorial Losada, 1949).

Von Tuhr, A., Tratado de las Obligaciones (trad. de Roces, W., Madrid, Reus, 1999). 